\title{
Amino acid turnover by elongating cattle blastocysts recovered on days 14-16 after insemination
}

\author{
D. G. Morris' ${ }^{1}$, P. G. Humpherson², H. J. Leese ${ }^{2}$ and J. M. Sreenan ${ }^{1}$ \\ ${ }^{1}$ Animal Reproduction Department, Teagasc, Agriculture and Food Development Authority, \\ Athenry, Co. Galway, Ireland; and ${ }^{2}$ Department of Biology, University of York, PO Box 373, \\ York YO10 5YW, UK
}

\begin{abstract}
Blastocyst elongation from day 14 to day 16 after insemination coincides with a major phase of embryo loss in cattle. Protein synthesis, reflected in protein content, increases markedly over this period but little is known about the amino acid requirement of elongating blastocysts at this time. Cattle blastocysts produced in vivo were recovered on days 14-16 after insemination and cultured individually for up to $8 \mathrm{~h}$ in synthetic oviduct fluid containing a physiological mixture of amino acids plus $1 \mathrm{mmol}$ glutamine $\mathrm{I}^{-1}$ and $0.1 \%(\mathrm{w} / \mathrm{v})$ polyvinyl alcohol (SOFaaPVA). After 1, 4 and $8 \mathrm{~h}$ in culture, an aliquot of culture medium was removed and the rate of amino acid depletion or production was calculated per unit of protein and per hour of culture. Amino acids were depleted or
\end{abstract}

produced at different rates. Arginine was depleted from the medium at a significant rate $(P<0.05)$ during all culture periods. Alanine and glutamate were produced at a significant rate $(P<0.05)$ during all culture periods. The rate of alanine production was significantly greater $(P<0.05)$ in blastocysts recovered on day 14 compared with days 15 or 16 after insemination. Alanine production and arginine depletion tended to be greater in smaller embryos recovered on day 14 compared with larger and later stage embryos, indicating that earlier stage embryos may have higher metabolic activity than later stage embryos. Qualitatively, the pattern of amino acid consumption and production during elongation was similar to that shown from the zygote to early blastocyst stage.

\section{Introduction}

Protein synthesis by cattle embryos remains relatively constant between the zygote and the eight-cell stage embryo (Frei et al., 1989; Thompson et al., 1998). From the 8-16-cell stage, and with the onset of the maternal to zygote genome transition, protein synthesis increases markedly (Frei et al., 1989; Grealy et al., 1996; Thompson et al., 1998) with concomitant increases in glucose (Rieger et al., 1992; Thompson et al., 1996) and amino acid (Guader-Joly et al., 1997) turnover (that is, consumption and production). This period of increased protein synthesis and metabolic activity coincides with the process of embryo compaction at about day 6 . This process is followed, in turn, by blastocyst formation, hatching and elongation, which are accompanied by an exponential increase in embryo size and protein content (Grealy et al., 1996; Thompson et al., 1998; Morris et al., 2000). In the embryo, amino acids are required for protein synthesis and have further roles in metabolism (Gardner, 1998), as energy sources (Rieger and Guay, 1988), as nucleic acid precursors (Leese, 1991), as osmolytes (Steeves and Gardner, 1999), as regulators of $\mathrm{pH}_{\mathrm{i}}$ (Bavister and McKiernan, 1993; Edwards et al., 1998) and as signalling molecules (Van Winkle, 2001). Amino acids

Email: dmorris@athenry.teagasc.ie are present in the oviduct and uterine fluids of cattle; alanine, glutamate and glycine are present in the highest concentrations (Moore and Bondioli, 1993; Guerin et al., 1995; Elhassan et al., 2001). Amino acid supplementation of culture media has been used to improve the developmental rate of matured, fertilized and cultured cattle embryos in vitro (Moore and Bondioli, 1993; Pinyopummintr and Bavister, 1996). Eckert et al. (1998) showed that in vitro culture, in the absence of protein or amino acids, results in a significant reduction in the proportion of cattle embryos developing to blastocysts. Partridge and Leese (1996) hypothesized a changing requirement for amino acids during early preimplantation cattle embryo development, whereas Steeves and Gardner (1999) demonstrated temporal and differential effects of amino acids on cattle embryo development during in vitro culture. Embryos depend on their uterine environment to sustain the exponential growth rates recorded between blastocyst formation at day 7 and day 8 and the elongated stage at day 16 after insemination (Grealy et al., 1996; Morris et al., 2000); this period coincides with the phase of greatest embryo loss in cattle (Diskin and Sreenan, 1980). During this period, because of increased metabolism and protein synthesis, embryos may be more susceptible to environmental stress or other conditions that alter their uterine environment. Indeed, amino acid concentrations in the bovine uterus are affected by heat stress and by the 
hormonal environment (Roussel and Loe, 1973). Although turnover of amino acids by cattle oocytes, zygotes and early stage embryos up to the blastocyst stage has been documented (Partridge and Leese, 1996; Jung et al., 1998), there are no reports on amino acid turnover at the time of blastocyst elongation, a period of rapid growth (Grealy et al., 1996; Morris et al., 2000) and a further critical period in cattle embryo development, after which time most embryos form fetuses that are carried to term (Diskin and Sreenan, 1980). An understanding of amino acid turnover by elongating cattle blastocysts is necessary to understand why this period of development is so susceptible to embryo loss. Therefore, the objective of the present study was to measure amino acid turnover by cattle blastocysts over the period of maximum elongation, from day 14 to day 16 after insemination.

\section{Materials and Methods}

\section{Embryo recovery}

Recovery of embryos produced in vivo was carried out as described by Morris et al. (2000). In brief, Hereford-cross heifers were superovulated by the i.m. administration of 1500 iu equine chorionic gonadotrophin (eCG) (Folligon, Intervet UK Ltd, Cambridge) during the mid-luteal phase of the oestrous cycle (days 10-14) and $500 \mu \mathrm{g}$ cloprostenol (Estrumate, Coopers Animal Health Ltd, Berkhamsted) $48 \mathrm{~h}$ later to induce luteolysis. After administration of cloprostenol, the heifers were examined continuously for overt signs of oestrus and those heifers observed in standing oestrus were artificially inseminated by an operator using semen from one sire. Embryo recovery was carried out during midventral laparotomy performed under licence in accordance with the European Community Directive, 86-609-EC. Anaesthesia was induced with thiopentone sodium (5 g, i.v.; Rhone Merieux, Harlow) and maintained by inhalation of halothane (May and Baker Ltd, Dagenham) in oxygen in a closed-circuit apparatus. On days 14-16 after insemination, embryos were flushed from the uterus using a two-way Foley French 14-gauge catheter with a $30 \mathrm{ml}$ balloon (Rusch Inc, NY). The composition of the flushing medium

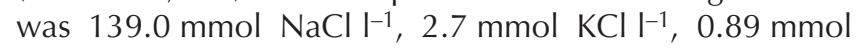
$\mathrm{CaCl}_{2} \cdot 2 \mathrm{H}_{2} \mathrm{O} \mathrm{I}^{-1}, \quad 1.47 \mathrm{mmol} \mathrm{KH}_{2} \mathrm{PO} 4 \mathrm{I}^{-1}, \quad 0.49 \mathrm{mmol}$ $\mathrm{MgCl}_{2} \cdot 6 \mathrm{H}_{2} \mathrm{Ol}^{-1}, 7.46 \mathrm{mmol} \mathrm{Na} 2 \mathrm{HPO}_{4} \cdot 2 \mathrm{H}_{2} \mathrm{Ol}^{-1}, 1.0 \mathrm{mmol}$ glucose $\mathrm{I}^{-1}, 0.5 \mathrm{mmol}^{2}$ sodium pyruvate $\mathrm{I}^{-1}$ and $0.1 \%(\mathrm{w} / \mathrm{v})$ polyvinyl alcohol, $\mathrm{pH} 7.3$.

\section{Embryo culture}

The culture medium used was synthetic oviduct fluid (Tervit et al., 1972) with 20 essential and non-essential amino acids at concentrations identical to those present in minimum essential medium (MEM) plus $1 \mathrm{mmol}$ glutamine $\mathrm{l}^{-1}$ (Table 1) and $0.1 \%$ polyvinyl alcohol (SOFaaPVA). After recovery, embryos were washed individually three times in $3 \mathrm{ml}$ flushing medium followed by three washes in $3 \mathrm{ml}$ Hepes buffered SOFaaPVA, followed by three washes in bicar-
Table 1. Concentrations of essential and non-essential amino acids present in the culture medium SOFaaPVA

\begin{tabular}{lclc}
\hline Amino acid & $\begin{array}{c}\text { Concentration } \\
\left(\mathrm{mmol} \mathrm{I}^{-1}\right)\end{array}$ & Amino acid & $\begin{array}{c}\text { Concentration } \\
\left(\mathrm{mmol} \mathrm{I}^{-1}\right)\end{array}$ \\
\hline Alanine & 0.10 & Leucine & 0.40 \\
Arginine & 0.73 & Lysine & 0.50 \\
Asparagine & 0.10 & Methionine & 0.10 \\
Aspartic acid & 0.10 & Phenylalanine & 0.20 \\
Cysteine & 0.20 & Proline & 0.10 \\
Glutamic acid & 0.10 & Serine & 0.10 \\
Glutamine & 1.00 & Threonine & 0.40 \\
Glycine & 0.10 & Tryptophan & 0.05 \\
Histidine & 0.27 & Tyrosine & 0.20 \\
Isoleucine & 0.40 & Valine & 0.40 \\
\hline
\end{tabular}

SOFaaPVA: synthetic oviduct fluid with 20 essential and non-essential amino acids plus 1 mmol glutamine $\mathrm{I}^{-1}$ and $0.1 \%$ polyvinyl alcohol.

bonate buffered SOFaaPVA. Embryos recovered on day 14 $(n=11)$, day $15 \quad(n=12)$ and day $16 \quad(n=13)$ after insemination were cultured individually in $500 \mu \mathrm{l}$ of the third wash (embryo medium) in Falcon tubes for up to $8 \mathrm{~h}$ at $38.5 \pm 0.5^{\circ} \mathrm{C}$ under a humidified atmosphere of $5 \% \mathrm{CO}_{2}$, $5 \% \mathrm{O}_{2}$ and $90 \% \mathrm{~N}_{2}$. After embryo removal, a $500 \mu \mathrm{l}$ aliquot of the third wash (embryo wash) was also cultured as a control for each embryo. Measurements were made at three time points to validate the in vitro system as a means of assessing amino acid metabolism. After 1, 4 and $8 \mathrm{~h}$ in culture, a $50 \mu \mathrm{l}$ aliquot was removed from each tube, snapfrozen in liquid nitrogen and stored at $-80^{\circ} \mathrm{C}$. At each of these time points, the culture medium was replenished with a $50 \mu \mathrm{l}$ aliquot of fresh medium. At the end of the $8 \mathrm{~h}$ culture period, embryos recovered on days 14-15 after insemination were washed four times in $3 \mathrm{ml}$ cold $\left(4^{\circ} \mathrm{C}\right)$ $10 \mathrm{mmol} \mathrm{PBS}^{-1}$ in $35 \mathrm{~mm}$ dishes. As embryos recovered on day 16 after insemination are more prone to disintegration, they were washed by gentle agitation in an Eppendorf tube containing $2 \mathrm{ml}$ of cold PBS, followed by centrifugation at $15000 \mathrm{~g}$ for $10 \mathrm{~min}$; these steps were repeated three more times. After washing, all the embryos were frozen in Eppendorf tubes at $-80^{\circ} \mathrm{C}$ in $5-10 \mu$ I PBS until used for assay. After thawing, the protein content of the embryos was measured (Grealy et al., 1996) using the bicinchoninic acid reagent (Pierce microBCA reagent, Perbio Science).

\section{Amino acid analysis}

Amino acid analysis was carried out using the procedure described by Lamb and Leese (1984) and Partridge and Leese (1996). Amino acids are reacted with o-phthaldialdehyde to yield highly fluorescent products which are analysed by reverse-phase high pressure liquid chromatography (HPLC). Cysteine and proline could not be detected by this method. For each embryo, a series of amino acid analyses was carried out on an aliquot of the embryo wash followed 
by an aliquot of the embryo medium at 1,4 and $8 \mathrm{~h}$, respectively. For each embryo, a standard amino acid mixture containing 18 amino acids was also analysed to determine the absolute concentrations of amino acids in the spent culture media. The amino acid concentrations found in the medium collected at 4 and $8 \mathrm{~h}$ were corrected for the removal of $50 \mu \mathrm{l}$ spent medium at the end of the 1 and $4 \mathrm{~h}$ time points and the addition of $50 \mu \mathrm{l}$ fresh medium at the beginning of the 4 and $8 \mathrm{~h}$ time points, respectively. The HPLC assay coefficient of variation was $15.3 \%(n=36)$, determined from an aliquot of culture medium analysed with each embryo. The protein content of each embryo was used to calculate amino acid utilization in pmol per $\mu \mathrm{g}$ protein per hour.

\section{Statistical analyses}

Amino acid depletion or production per $\mu \mathrm{g}$ embryo protein per hour was calculated to normalize for differences in embryo protein content and duration of culture. Amino acid depletion or production during each of the three culture periods was tested for significance from zero by the Student's $t$ test. Differences between days or culture periods were analysed by Proc GLM (version 8.01, SAS 2001) to fit a model that allowed for the repeated measures made on the same heifer and included the effect of heifer within days. The main effects of day and culture period and day $\times$ culture period interaction were tested using the heifer within-day mean square as the error term. Significant differences were compared using the Tukey-Kramer option within SAS. Data were log transformed to approximate normal variates before analysis. A probability value of $P<0.05$ was considered significant. Values are presented as arithmetic means \pm SEM.

\section{Results}

Amino acid depletion and production rates pooled across days for elongated cattle blastocysts recovered on days 14-16 after insemination, during 1, 4 and $8 \mathrm{~h}$ in culture are shown (Figs $1-3$, respectively). There was no day $\times$ culture period interaction on amino acid depletion or production. The depletion or production rates of individual amino acids differed among culture periods. Amino acid depletion was more variable among embryos during the $1 \mathrm{~h}$ culture period than during the 4 and $8 \mathrm{~h}$ culture periods; however, the pattern of depletion or production was generally independent of culture period. Glutamate and alanine were produced during all culture periods at significant $(P<0.05)$ to highly significant $(P<0.001)$ rates (Figs $1-3)$. Glycine was produced at a significant $(P<0.01)$ to highly significant $(P<0.001)$ rate during the 4 and $8 \mathrm{~h}$ culture periods, respectively, whereas methionine and valine were produced at a significant rate $(P<0.05)$ during the $8 \mathrm{~h}$ culture period only. Arginine was depleted from the medium at a significant $(P<0.05)$ to highly significant $(P<0.001)$ rate during all culture periods. Aspartate was

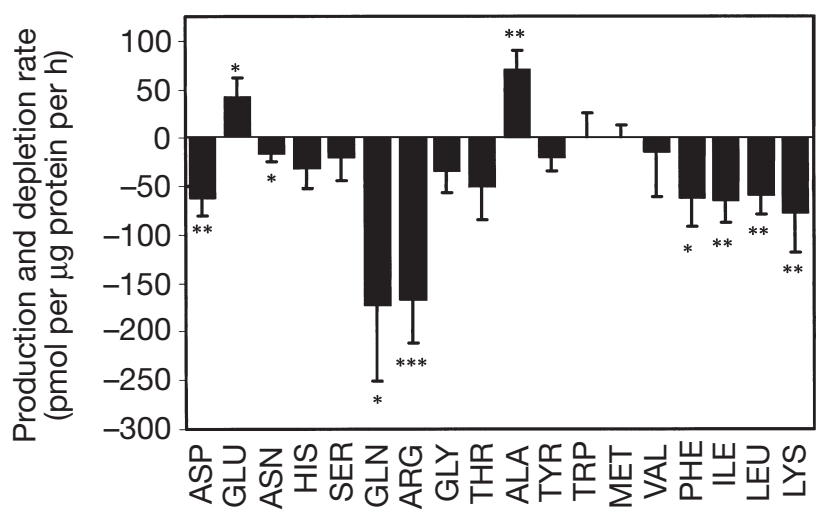

Amino acid

Fig. 1. Amino acid production and depletion rates (mean \pm SEM) by cattle blastocysts at days 14, 15 and 16 after insemination, during $0-1 \mathrm{~h}$ of culture ( $1 \mathrm{~h}$ period) in SOFaaPVA containing a physiological mixture of amino acids. Results for all days are combined and are expressed as pmol per $\mu \mathrm{g}$ protein per hour. ${ }^{*} P<0.05, \quad{ }^{* *} P<0.01, \quad{ }^{* * *} P<0.001$ compared with zero depletion.

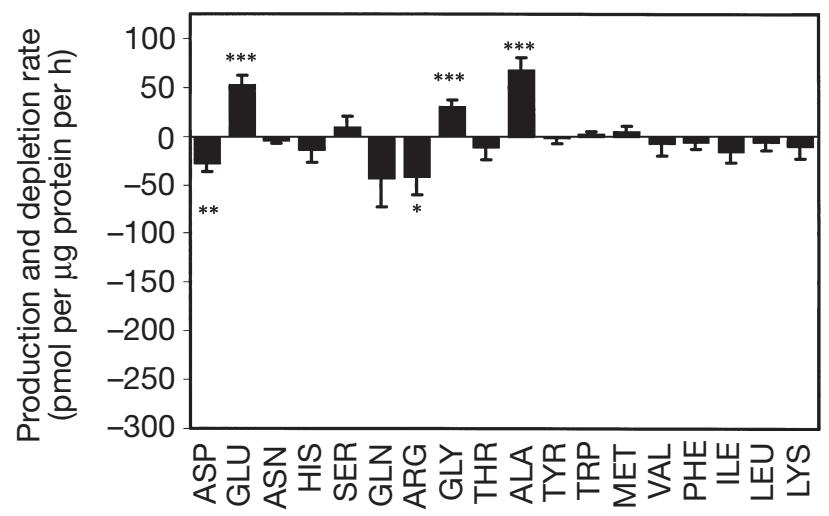

Amino acid

Fig. 2. Amino acid production and depletion rates (mean \pm SEM) by cattle blastocysts at days 14, 15 and 16 after insemination, during $1-4 \mathrm{~h}$ of culture ( $4 \mathrm{~h}$ period) in SOFaaPVA containing a physiological mixture of amino acids. Results for all days are combined and rates are expressed as pmol per $\mu$ g protein per hour. $* P<0.05, \quad * * P<0.01, \quad{ }^{* * *} P<0.001 \quad$ compared with zero depletion.

depleted in a significant manner during the 1 and $4 \mathrm{~h}$ culture periods $(P<0.01)$, whereas asparagine, phenylalanine, isoleucine, leucine and lysine were depleted at a significant rate $(P<0.05)$ during the $1 \mathrm{~h}$ culture period only. The rate of isoleucine depletion was significantly higher $(P<0.05)$ during the $1 \mathrm{~h}$ period compared with during the $8 \mathrm{~h}$ culture period. There was no effect of time on the rate of depletion or production of any of the other amino acids.

The rate of alanine production pooled across culture periods was higher in embryos recovered on day 14 $(P<0.05)$ compared with embryos recovered on day 15 or 


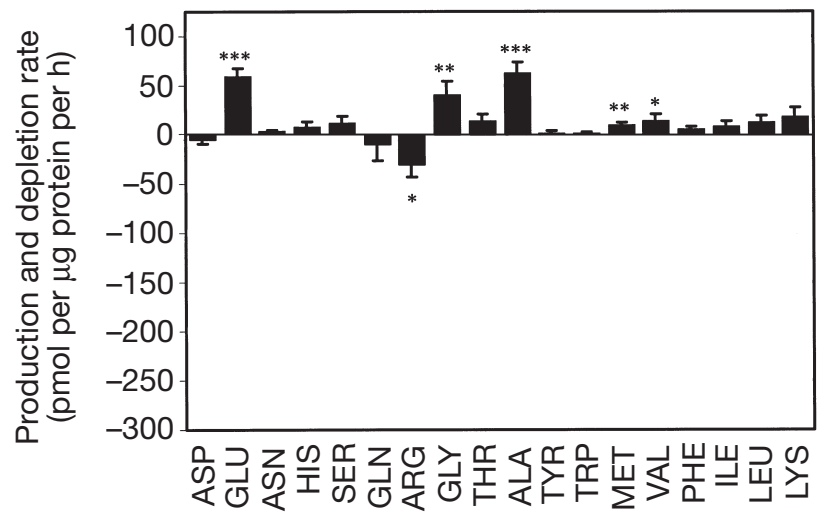

Amino acid

Fig. 3. Amino acid production and depletion rates (mean \pm SEM) by cattle blastocysts at days 14,15 and 16 after insemination, during $4-8 \mathrm{~h}$ in culture ( $8 \mathrm{~h}$ period) in SOFaaPVA containing a physiological mixture of amino acids. Results for all days are combined and rates are expressed as pmol per $\mu$ g protein per hour. ${ }^{*} P<0.05, \quad{ }^{* *} P<0.01, \quad{ }^{* * *} P<0.001 \quad$ compared with zero depletion.

day 16 (Fig. 4) and tended to be higher for the earlier stage and smaller embryos compared with the later and larger embryos recovered on day 14 after insemination (Fig. 5). Glutamate production pooled across culture periods also tended to be higher in embryos recovered on day 14 compared with embryos recovered on day 15 or day 16 after insemination and followed a similar pattern to alanine production (Fig. 4); however, this difference was not significant. Arginine depletion pooled across culture periods also tended to be higher in embryos recovered on day 14 compared with embryos recovered on day 15 or day 16 after insemination (Fig. 4); however, this difference was not significant. In a similar manner to alanine production, arginine depletion also tended to be higher for the earlier stage and smaller embryos recovered on day 14 compared with the later and larger embryos recovered on day 14 after insemination (Fig. 6). Irrespective of embryo age, alanine and glutamate appearance and arginine depletion in the medium tended to be greatest in smaller embryos. Depletion and production rates were not different between days for any of the other amino acids.

\section{Discussion}

This is thought to be the first report to describe amino acid turnover by elongating cattle blastocysts recovered on days 14-16 after insemination. The individual amino acid requirements of cattle embryos recovered on days 14-16 after insemination varied widely, and many amino acids were depleted at different rates whereas others were produced by embryos. Differences in the individual rate of amino acid turnover may be the result of differences in the concentrations of amino acids present in the culture medium and, in turn, competition between amino acids for amino acid transporters. However, the relationship between amino acid concentrations in the medium and turnover by embryos was not addressed in the present study. The results show that the rate of amino acid depletion was generally higher during the $1 \mathrm{~h}$ period of culture compared with the 4 and $8 \mathrm{~h}$ culture periods; however, the rate of amino acid production was similar across culture periods. The rate of depletion during $1 \mathrm{~h}$ of culture probably reflects the way in which the embryo adapts to an in vitro culture environment, whereas the depletion or production rates during 4 and $8 \mathrm{~h}$ of culture are more likely to reflect a steady state of amino acid turnover. Glutamine and arginine were depleted numerically at the greatest rate, especially during the $1 \mathrm{~h}$ culture period. Glutamine is present at relatively low concentrations in the bovine oviduct and uterine fluids, whereas glycine is the most abundant amino acid (Moore and Bondioli, 1993; Solymosi and Horn, 1994; Guerin et al., 1995; Elhassan et al., 2001). However, glutamine is the preferred amino acid of bovine zygotes produced in vitro and of four-cell embryos (Partridge and Leese, 1996) and has been shown to improve embryonic development during in vitro culture. In addition to pyruvate and glycine, oxidative metabolism of glutamine is the major energy-producing pathway in cattle oocytes (Rieger et al., 1992) at a time when high concentrations of glucose are detrimental to embryo development. However, the rate of glutamine consumption is relatively low by the time the cattle embryo reaches the blastocyst stage at day 7 after insemination (Rieger et al., 1992; Partridge and Leese, 1996; Jung et al., 1998). However, glutamine consumption increases again during blastocyst expansion (Rieger et al., 1992; Tiffin et al., 1991), at which stage glucose consumption too has increased markedly. In the present study, by the time the blastocyst begins to elongate, glutamine is one of the preferred amino acids. Glutamine is thought to have a dual role during bovine embryo development, including that of an osmolyte and an energy source (Steeves and Gardner, 1999). Arginine was the only amino acid depleted at a significant rate during all culture periods. Arginine depletion has also been reported for cattle blastocysts produced in vivo at day 7 after insemination (Partridge and Leese, 1996) and by morulae and blastocysts produced in vitro (Lee and Fukui, 1996). In the present study, arginine depletion also tended to be greatest in early stage embryos recovered on day 14 compared with later stage embryos recovered on days 14-16 after insemination. Arginine acts as a substrate for nitric oxide synthesis, which is essential for mouse embryo growth and development (Gouge et al., 1998; Chen-Huei-Wen, 2001). Arginine is thought to promote the growth of blastocysts by increasing the supply of nutrients and also by signalling that results in an increase in the capacity for, and rate of, protein synthesis (Van Winkle, 2001). The tendency for the rate of arginine depletion to decrease from the early stage blastocyst at day 14 to blastocysts at days 15-16 after insemination observed in the present study is in agreement with a decrease in the rate of protein synthesis reported by Morris et al. (2000) for 


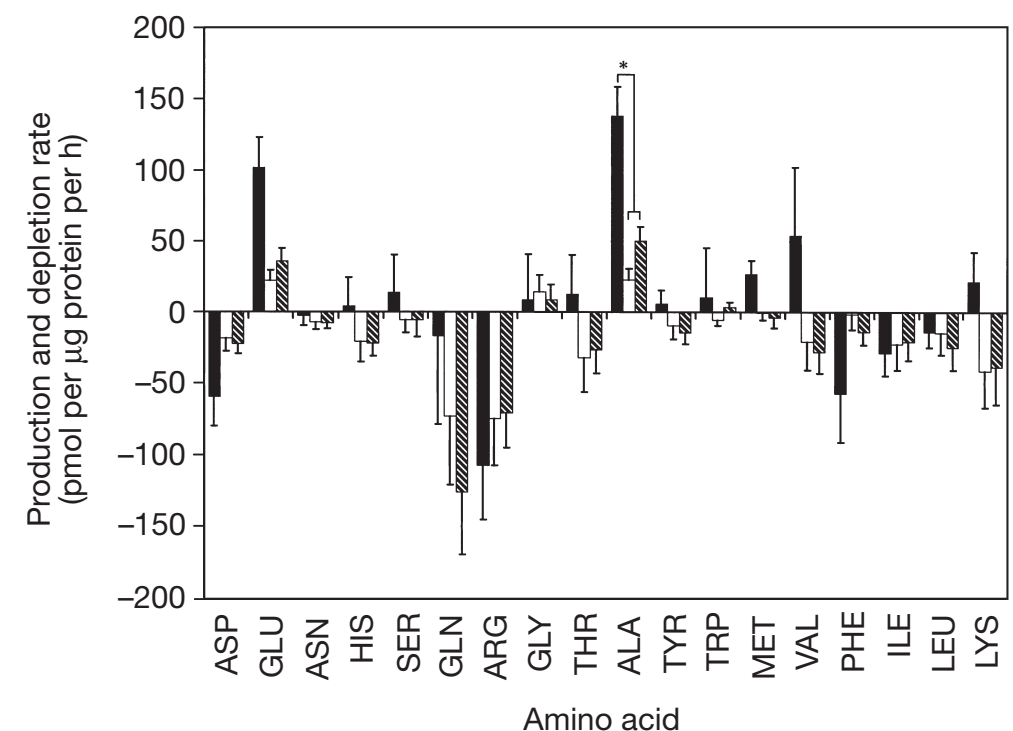

Fig. 4. Comparison of amino acid production and depletion rates (mean \pm SEM) among cattle blastocysts at day $14(\boldsymbol{\square})$, day $15(\square)$ and day 16 after insemination $(\mathbb{\mathbb { N }})$ after culture in SOFaaPVA containing a physiological mixture of amino acids. Results for all culture periods are combined and rates are expressed as pmol per $\mu \mathrm{g}$ protein per hour. Asterisk denotes significant difference: $P<0.05$.

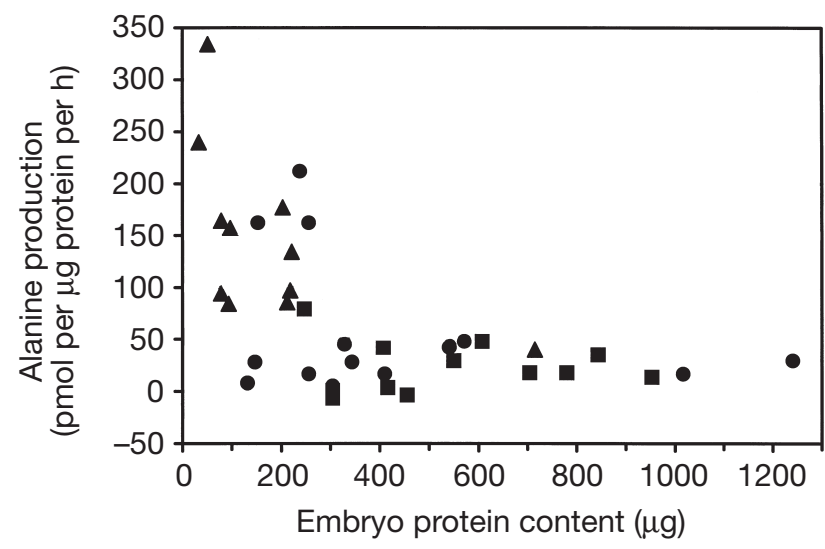

Fig. 5. Alanine production as a function of embryo protein content by cattle blastocysts at day $14(\mathbf{\Delta})$, day $15(\boldsymbol{\square})$ and day 16 after insemination (-) after culture in SOFaaPVA containing a physiological mixture of amino acids. Results for all culture periods are combined and rates are expressed as pmol per $\mu$ g protein per hour.

blastocysts at day 15 compared with blastocysts at day 14 after insemination. Nitric oxide can regulate cGMP concentrations, and inhibition of nitric oxide synthesis decreases cGMP concentrations in rat endometrium (Durán-Reyes et al., 1999). A decrease in the cGMP content per unit of protein of cattle blastocysts at days 15-16 compared with blastocysts at day 14 after insemination was reported by Grealy et al. (1997) and Grealy and Sreenan (1999) and is consistent with the tendency for arginine

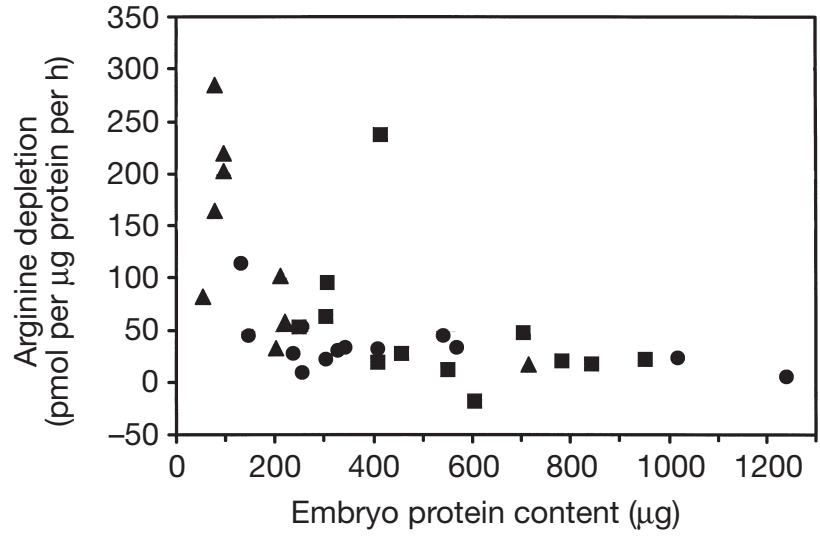

Fig. 6. Arginine depletion as a function of embryo protein content by cattle blastocysts at day $14(\mathbf{A})$, day 15 (口) and day 16 after insemination (-) after culture in SOFaaPVA containing a physiological mixture of amino acids. Results for all culture periods are combined and rates are expressed as pmol per $\mu \mathrm{g}$ protein per hour.

depletion in the present study to be lower in cattle blastocysts at days 15-16 compared with blastocysts at day 14 after insemination.

An unexpected result, although consistent with reports by Partridge and Leese (1996), Jung et al. (1998) and McEvoy et al. (2000) for cattle blastocysts at day 7 after insemination, was the highly significant production of alanine by embryos at all culture periods. Alanine production is also a feature of embryos produced in vitro 
from the putative zygote to the day 7 blastocyst stage (Partridge and Leese, 1996). Alanine production or output may be a mechanism by which embryos export intracellular ammonia, a by-product of metabolism, a build up of which would be toxic (Gardner and Lane, 1993; Gardner et al., 1994; Lane and Gardner, 1994). The production of glutamate is not a feature of early embryonic stages (Partridge and Leese, 1996; Jung et al., 1998), but in the present study may be an additional mechanism for ammonia disposal in the elongating blastocyst via glutamate dehydrogenase. Ammonia is an inevitable product of the metabolism of amino acids, and as such, alanine or glutamate output may be considered useful markers of protein turnover. Indeed, when alanine production was related to embryo protein content, smaller embryos tended to have a higher rate of alanine production and, by inference, a higher metabolic rate than larger and later stage embryos. This finding is in agreement with a study by Morris et al. (2000) in which the rate of protein synthesis by blastocysts at day 13 was found to be higher than that by blastocysts at days 14-15 after insemination. The consistent production of these amino acids in the face of a changing pattern of consumption indicates that this export mechanism operates to full capacity in these embryos. However, although the consumption of individual amino acids tended to be greater during the early culture periods, glutamate and alanine were produced by the embryos at a consistent rate regardless of the culture period. In the present study, amino acid depletion or accumulation is reported on a per embryo mass basis. No attempt was made to differentiate between amino acid depletion and production by the blastocoelic fluid and by the embryo per se, an impossible task, practically, in elongating cattle blastocysts. Large differences in the rates of depletion and production for other amino acids were also found among blastocysts at days 14-16 after insemination; however, these differences were not significant. This finding may, in part, be due to the numbers of embryos used in this study, although it is more likely to be the result of the naturally wide variation in developmental stage and size of embryos recovered on each day.

Overall, the pattern of amino acid consumption and production by expanding cattle blastocysts in the present study was similar to the pattern for cattle embryos at other developmental stages (Partridge and Leese, 1996; Jung et al., 1998). These data support previous reports of individual amino acid preferences by cattle embryos and the way in which amino acid preferences change throughout development. In future studies, it will be important to investigate how the requirements of the preimplantation cattle embryo are met by conditions in the uterine environment and how these requirements may, in turn, be affected by the maternal nutritional environment.

This work was supported by the EC Biotech $4^{\text {th }}$ Framework Programme (Contract No. CT-95-0190). The authors wish to thank A. Glynn, P. Joyce, G. Morris, W. Connolly and J. Nally for technical support, and G. Burke, P. Creavan and P. Reilly for care of the animals.

\section{References}

Bavister BD and McKiernan SH (1993) Regulation of hamster embryo development in vitro by amino acids. In Preimplantation Embryo Development pp 57-72 Ed. BD Bavister. Springer-Verlag, New York

Chen-Huei-Wen, Jiang-Wen-Sheng and Tzeng-Chii-Ruey (2001) Nitric oxide as a regulator in preimplantation embryo development and apoptosis Fertility and Sterility 75 1163-1171

Diskin MG and Sreenan JM (1980) Fertilization and embryonic mortality rates in beef heifers after artificial insemination Journal of Reproduction and Fertility $\mathbf{5 9} 463-468$

Durán-Reyes G, Gómez-Meléndez MDR, Morali-de la Brena G, MercadoPichardo E, Medina-Navarro R and Hicks-Gómez JJ (1999) Nitric oxide synthesis inhibition suppresses implantation and decreases cGMP concentration and protein peroxidation Life Sciences 65 2259-2268

Eckert J, Pugh PP, Thompson JG, Niemann H and Tervitt HR (1998) Exogenous protein affects developmental competence and metabolic activity of bovine preimplantation embryos in vitro. Reproduction, Fertility and Development $10327-332$

Edwards LJ, Williams DA and Gardner DK (1998) Intracellular pH of the mouse preimplantation embryo: amino acids act as buffers of intracellular $\mathrm{pH}$ Human Reproduction 13 3341-3348

Elhassan YM, Wu G, Leanez AC, Tasca RJ, Watson AJ and Westhusin ME (2001) Amino acid concentrations in fluids from the bovine oviduct and uterus and in KSOM-based culture media Theriogenology $\mathbf{5 5}$ 1907-1918

Frei RE, Schultz GA and Church RB (1989) Qualitative and quantitative changes in protein synthesis occur at the 8-16-cell stage of embryogenesis in the cow Journal of Reproduction and Fertility 86 637-641

Gardner DK (1998) Changes in requirements and utilisation of nutrients during mammalian preimplantation embryo development and their significance in embryo culture Theriogenology 49 83-102

Gardner DK and Lane M (1993) Amino acids and ammonium regulate mouse embryo development in culture Biology of Reproduction $\mathbf{4 8}$ 377-385

Gardner DK, Lane M, Spitzer A and Batt PA (1994) Enhanced rates of cleavage and development for sheep zygotes cultured to the blastocyst stage in vitro and in the absence of serum and somatic cells: amino acids, vitamins and culturing embryos in groups stimulate development Biology of Reproduction $\mathbf{5 0} 390-400$

Gouge RC, Marshburn P, Gordon BE, Nunley W and Huet-Hudson YM (1998) Nitric oxide as a regulator of embryonic development Biology of Reproduction 58 875-879

Grealy M and Sreenan JM (1999) Effect of adenyl cyclase activation on intracellular and extracellular CAMP and CGMP in preimplantation cattle blastocysts Journal of Reproduction and Fertility 116 355-361

Grealy M, Diskin MG and Sreenan JM (1996) Protein content of cattle oocytes and embryos from the two-cell to the elongated blastocyst stage at day 16 Journal of Reproduction and Fertility 107 229-233

Grealy M, Glynn MA and Sreenan JM (1997) Cyclic AMP and cyclic GMP concentrations in and efflux from preimplantation cattle embryos Animal Reproduction Science 48 175-185

Guader-Joly C, Khatchadourian C and Menezo Y (1997) Glycine and Methionine transport by bovine embryos Zygote 5 273-276

Guerin P, Gallois E, Croteau S, Revol N, Maurin F, Guillard J and Menezo Y (1995) Techniques de recolte et aminogrammes des liquides tubaire et folliculaire ches les femelles domestiques Revue Medicine Veterinaire 146 805-814

Jung YG, Sakata T, Lee ES and Fukui Y (1998) Amino acid metabolism of bovine blastocysts derived from parthenogenetically activated or in vitro fertilized oocytes Reproduction, Fertility and Development 10 279-287

Lamb VK and Leese HJ (1984) Uptake of a mixture of amino acids by mouse blastocysts Journal of Reproduction and Fertility 102 169-175

Lane M and Gardner DK (1994) Increase in postimplantation development of cultured mouse embryos by amino acids and induction of fetal 
retardation and encephaly by ammonium ions Journal of Reproduction and Fertility 102 305-312

Lee Eun-Song and Fukui Y (1996) Synergistic effect of alanine and glycine on bovine embryos cultured in a chemically defined medium and amino acid uptake by in vitro-produced bovine morulae and blastocysts Biology of Reproduction 55 1383-1389

Leese HJ (1991) Metabolism of the preimplantation mammalian embryo. In Oxford Reviews of Reproductive Biology pp 35-72 Ed. R Milligan. Oxford University Press, Oxford, UK

McEvoy TG, Kuran M, Browne D, Buchan V, McCallum GJ, Wilmut I, Sinclair KD and Robinson JJ (2000) Amino acid uptake by bovine embryos produced in different culture systems Theriogenology $\mathbf{5 3} 300$ (Abstract)

Moore K and Bondioli KR (1993) Glycine and alanine supplementation of culture medium enhances development of in vitro matured and fertilized cattle embryos Biology of Reproduction 48 833-840

Morris DG, Diskin MG and Sreenan JM (2000) Protein synthesis and phosphorylation by elongating 13-15 day-old cattle blastocysts Reproduction, Fertility and Development 12 39-44

Partridge RJ and Leese HJ (1996) Consumption of amino acids by bovine preimplantation embryos Reproduction, Fertility and Development $\mathbf{8}$ 945-950

Pinyopummintr T and Bavister BD (1996) Energy substrate requirements for in vitro development of early cleavage-stage bovine embryos Molecular Reproduction and Development 44 193-199

Rieger D and Guay P (1988) Measurement of the metabolism of energy substrates in individual bovine blastocysts Journal of Reproduction and Fertility 83 585-591

Rieger D, Loskutoff NM and Betteridge KJ (1992) Developmentally related changes in the uptake and metabolism of glucose, glutamine and pyruvate by cattle embryos produced in vitro. Journal of Reproduction and Fertility 4 547-557
Roussel JD and Loe WC (1973) Effects of heat stress and melengestero acetate on amino acid pattern of uterine fluid from dairy heifers International Journal of Biometerology 17 153-156

SAS (2001) SAS User's Guide: Statistics SAS Institute Inc., Cary, NC

Solmymosi F and Horn P (1994) Protein content and amino acid composition of the uterine milk in swine and cattle Acta Veterinaria Hungarica 42 487-494

Steeves TE and Gardner DK (1999) Temporal and differential effects of amino acids on bovine embryo development in culture Biology of Reproduction 61 731-740

Tervit HR, Whittingham DG and Rowson LEA (1972) Successful culture in vitro of sheep and cattle ova Journal of Reproduction and Fertility $\mathbf{3 0}$ 493-497

Thompson JG, Partridge RJ, Houghton FD, Cox CI and Leese HJ (1996) Oxygen uptake and carbohydrate metabolism by in vitro-derived bovine embryos Journal of Reproduction and Fertility 106 299-306

Thompson JG, Sherman AN, Allen NW, McGowan LT and Tervit HR (1998) Total protein content and protein synthesis within pre-elongation stage bovine embryos Molecular Reproduction and Development $\mathbf{5 0}$ 139-145

Tiffin GJ, Rieger D, Betteridge KJ, Yadav BR and King WA (1991) Glucose and glutamine metabolism in pre-attachment cattle embryos in relation to sex and stage of development Journal of Reproduction and Fertility 93 $125-132$

Van Winkle LJ (2001) Amino acid transport regulation and early embryo development Biology of Reproduction 64 1-12

Received 15 April 2002.

First decision 15 May 2002.

Revised manuscript received 12 June 2002.

Accepted 16 July 2002. 